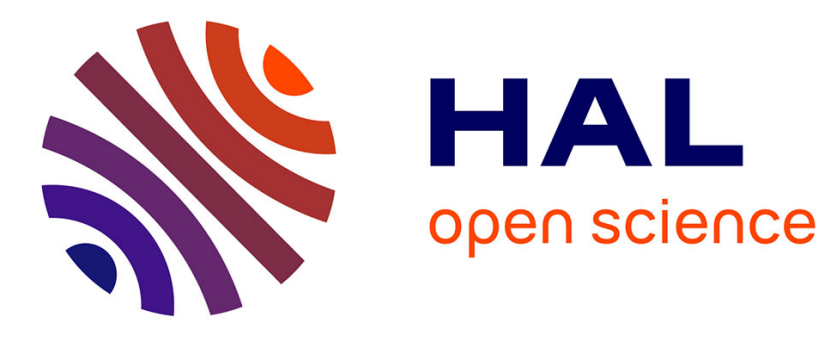

\title{
A Model to Evaluate Supply Chains in Disruption Events
}

\author{
Toma Kobayashi, Masaru Nakano
}

\section{To cite this version:}

Toma Kobayashi, Masaru Nakano. A Model to Evaluate Supply Chains in Disruption Events. IFIP International Conference on Advances in Production Management Systems (APMS), Sep 2015, Tokyo, Japan. pp.308-315, 10.1007/978-3-319-22759-7_36 . hal-01431110

\section{HAL Id: hal-01431110 https://hal.inria.fr/hal-01431110}

Submitted on 10 Jan 2017

HAL is a multi-disciplinary open access archive for the deposit and dissemination of scientific research documents, whether they are published or not. The documents may come from teaching and research institutions in France or abroad, or from public or private research centers.
L'archive ouverte pluridisciplinaire HAL, est destinée au dépôt et à la diffusion de documents scientifiques de niveau recherche, publiés ou non, émanant des établissements d'enseignement et de recherche français ou étrangers, des laboratoires publics ou privés.

\section{(c)(1)}

Distributed under a Creative Commons Attribution| 4.0 International License 


\title{
A Model to Evaluate Supply Chains in Disruption Events
}

\author{
Toma Kobayashi and Masaru Nakano \\ The Graduate School of System Design and Management, Keio University \\ Kyosei Building, 4-1-1, Hiyoshi, Kohoku-ku, Yokohama, Kanagawa, 223-8526, Japan \\ toma.k@keio.jp, nakano@sdm.keio.ac.jp
}

\begin{abstract}
Supply chain risk management is becoming increasingly necessary due to large-scale disasters. However, there is a trade-off between the long-term benefits of a supply chain and the disruption mitigation costs. Therefore, it is difficult to justify the high cost of risk countermeasures against such rare disruptions. Previous studies have discussed reducing risk in terms of mitigation and responsiveness to disruption events; however, many companies maintain low inventories and a single source supplier represented by just-intime or lean manufacturing. Through interviews, we found that in addition to providing long-term benefits, maintaining low inventory can increase the efficiency of recovery activities. This study clarifies the effectiveness of a buffer inventory while considering risk mitigation and responsiveness by creating an evaluation model. A simulation model is used to determine the relationship between disruption time and buffer inventory.
\end{abstract}

Keywords: Supply chain, Disruption events, Supply chain risk management, Evaluation model

\section{Introduction}

Recently, many industries and logistic networks have experienced disruptions due to large-scale disasters, such as the Great East Japan Earthquake and the 2011 Thailand floods. The effects of such disruptions extend to companies that do not suffer direct damage and significantly affect the entire supply chain. Thus, supply chain risk management is becoming increasingly necessary (Kleindorfer \& Saad, 2005). However, there is a trade-off between the long-term benefits of maintaining a supply chain and the cost to mitigate disruption risks (Sheffi, 2005). It is difficult to justify the high costs involved in implementing countermeasures to guard against such rare disruptions. Therefore, quantitative methods and evaluation criteria to determine the vulnerability and risk to the entire supply chain are necessary. Previous studies have discussed reducing risk in terms of mitigation and responsiveness to disruption events (Knemeyer, Zinn, \& Eroglu, 2009; Tomlin, 2006). Many companies practice just-in-time or lean manufacturing, e.g., carrying low inventories and relying on a single source supplier, even though those strategies are vulnerable to disruption risks. Through interviews, we found that in addition to providing long-term benefits, maintaining a low inventory can increase the efficiency of recovery activities.

Previous studies have suggested that maintaining a buffer inventory can mitigate supply chain disruptions (Song \& Zipkin, 1996; Tomlin, 2006). However, no studies 
have considered the negative effect of a buffer inventory on recovery activities. Therefore, this study was conducted to develop an evaluation model to clarify the conditions whereby a buffer inventory is effective to mitigate disruptions taking risk mitigation and responsiveness into consideration. We have created a mathematical supply chain model and determined the relationship between inventory and recovery activities. Finally, we considered a disruption scenario and conducted a numerical experiment.

This remainder of this paper is as follows. Section 2 explains the principal countermeasures against disruption events through a literature review and defines the relationship between recovery activities and inventory. Section 3 describes the proposed model. In section 4, we present the results of our numerical experiment. Section 5 concludes the study and identifies opportunities for further research.

\section{Literature review}

\subsection{Supply chain risk management}

Studies of business continuity plans for supply chains are often divided into three groups: the probability of the occurrence of risks, direct damage to each node, and the disruption of the entire supply chain due to the effects on a single node. This study is primarily concerned with the latter. Tainton \& Nakano (2014) identified behavioral patterns of manufacturing supply chains under the effects of extreme events. Figure 1 shows the disruption pattern when the supply is changed and recovery activities related to disruption events. In general, disruption risk management is classified into risk mitigation and responsiveness (Knemeyer et al., 2009; Tomlin, 2006). In other words, disruption risk management consists of provisions to avoid disruption and action plans that can be implemented after a disruption. From risk mitigation perspective, previous studies have primarily suggested maintaining a buffer inventory (Song \& Zipkin, 1996; Tomlin, 2006), diversifying suppliers (Dada, Petruzzi, \& Schwarz, 2007; Tomlin \& Wang, 2005; Tomlin, 2009), and strengthening the trust among suppliers (Krause, 1997; Krause, Handfield, \& Tyler, 2007). Relative to responsiveness strategies, previous studies proposed using alternative or backup suppliers (Chopra, Reinhardt, \& Mohan, 2007; Tomlin, 2006; Tomlin, 2009) and employing management that is capable of flexibly responding to changing production plans (Tomlin, 2009). Each of these strategies has advantages and disadvantages. Moreover, risk mitigation and responsiveness are related. Therefore, companies must carefully consider both aspects and manage or combine strategies depending on the situation. Note that each strategy incurs costs, which affects the long-term benefits of a supply chain. 


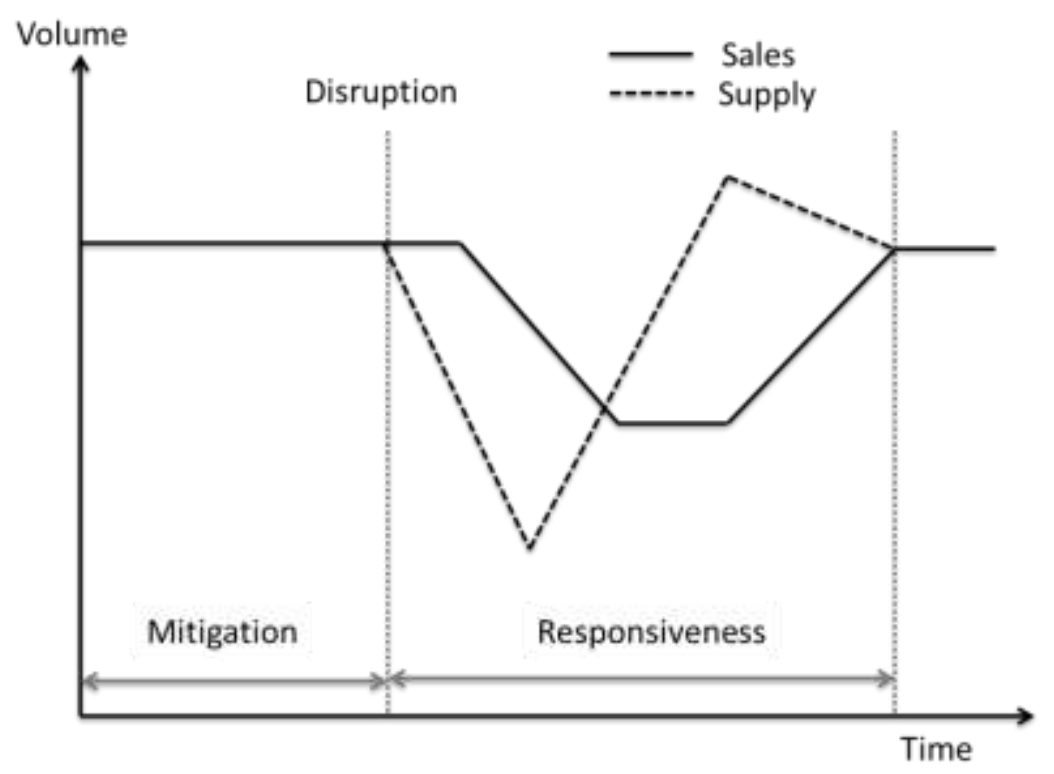

Fig. 1 Supply disruption and recovery activities

\subsection{Relationship between recovery activities and inventory}

As indicated in previous studies, maintaining a buffer inventory and diversifying suppliers can mitigate damage due to disruption events (Song \& Zipkin, 1996; Tomlin, 2006). On the other hand, many companies maintain low inventories and a single source supplier represented by just-in-time or lean manufacturing. Through interviews with a production manager, we found this strategy can provide long-term benefits, and maintaining low inventory can increase the efficiency of recovery activities. If companies maintain a buffer inventory, those that do not suffer direct damage can continue producing based on the production plan in place at the time of disruption. Therefore, where the disruption event occurs is not immediately evident, and such companies cannot comprehend why they should invest in recovery plans. On the other hand, when a disruption event occurs, if companies do not carry a buffer inventory, production stops very quickly. Consequently, companies that suffer directly immediately grasp the problem, and all companies in the supply chain can participate in recovery activities.

Figure 2 illustrates the relationship between a buffer inventory and other parameters. 


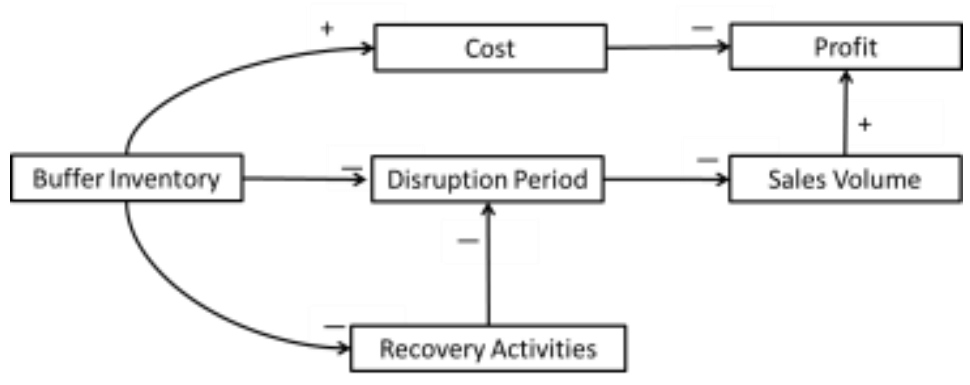

Fig. 2 Relationship between buffer inventory and other parameters

Maintaining a buffer inventory can mitigate disruption time; however, it incurs cost and can have negative effect on recovery activities.

\section{Simulation Model}

\subsection{Definition and formulation of supply chain model}

In this study, we consider a supply chain that consists of three companies. Figure 3 shows the model structure.

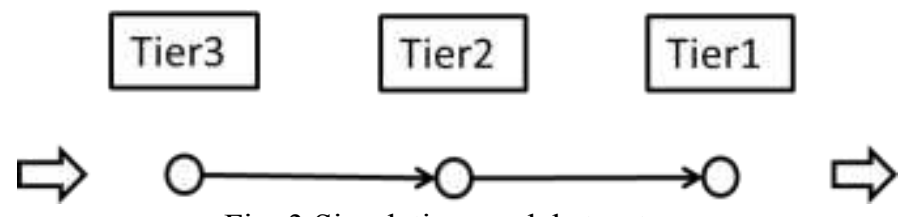

Fig. 3 Simulation model structure

For each period $t$, we define the following:

$O_{t}^{i}$ : output inventory of supplier $i$ at period $t$

$I_{t}^{i}$ : input inventory of supplier $i$ at period $t$

$M_{t}^{i}$ : production volume of supplier $i$ at period $t$

$D_{t}^{i}$ : order volume of supplier $i$ at period $t$

$S_{t}^{i}$ : sales volume of supplier $i$ at $t$

The rules of the model are as follows:

- Demand is constant through the simulation $\left(D_{t}^{0}=D\right)$.

- Each supplier orders the same amount as it has been receiving from its upper supplier (insert the equation).

- Delivery takes one period. 
- Each company has the same inventory quantity before the simulation begins $\left(I_{o}^{i}=I\right)$.

- The sales volume of tier 4 is the same as the orders of tier $3\left(S_{t}^{4}=D_{t}^{3}\right)$.

The model formulas are as follows:

$$
\begin{gathered}
O_{t}^{i}=O_{t-1}^{i}+M_{t}^{i}-S_{t}^{i} \\
I_{t}^{i}=I_{t-1}^{s}-M_{t}^{i}+S_{t}^{i+1} \\
M_{t}^{i}=\min \left\{D_{t-1}^{i-1}, I_{t-1}^{i}\right\} \\
S_{t}^{i}=\min \left\{D_{t-1}^{i-1}, O_{t}^{i}+M_{t}^{i}\right\} \\
M_{t}^{4}=D_{t}^{3}
\end{gathered}
$$

\subsection{Disruption and recovery model}

The problem of maintaining a buffer inventory in terms of responsiveness is if companies maintain a buffer inventory, each company that does not suffer direct damage continues producing based on the production plan at the time of the disruption; thus, the problem can be difficult to identify. Consequently, it becomes difficult to justify committing resources to recovery. To model this phenomenon, we have designed a simulation model by defining the conditions of disruption, recovery, and participation in recovery activities for each tier as follows:

- A disruption event occurs at tier 3 .

- Tier 3 cannot produce, sell, or order during a disruption.

- Each tier engages in recovery activities when production is halted, which helps express how an inventory buffer can affect recovery.

Here, we define the following:

$R$ : total recovery amount

$R_{c}:$ recovery constant

$r_{i}$ : recovery amount of tier $\mathrm{i}$ at period $t$

$\Pi_{R}:$ set of tiers that engage in recovery activities

$t_{d}:$ disruption period

When the following condition is satisfied, recovery activities are completed and tier 3 resumes normal production, sales, and ordering.

$$
R=\sum_{t=1}^{t_{d}} \sum_{i \in \Pi_{R}} r_{i} \geq R_{c}
$$


The simulation model follows the flowcharts shown in Figs. 4 and 5.

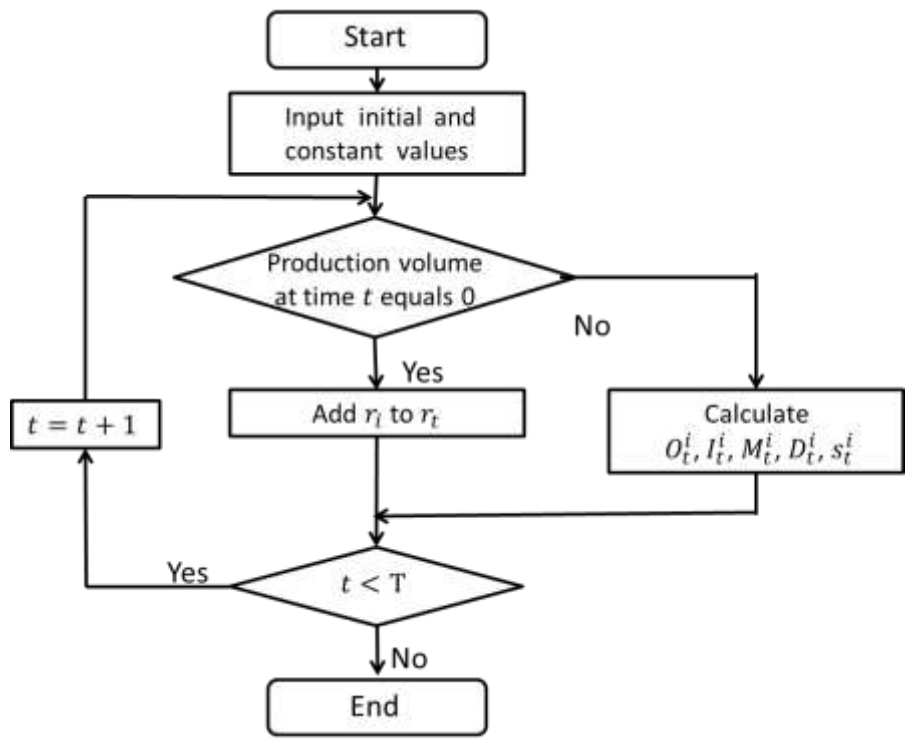

Fig. 4 Flowcharts for tiers 1 and 2

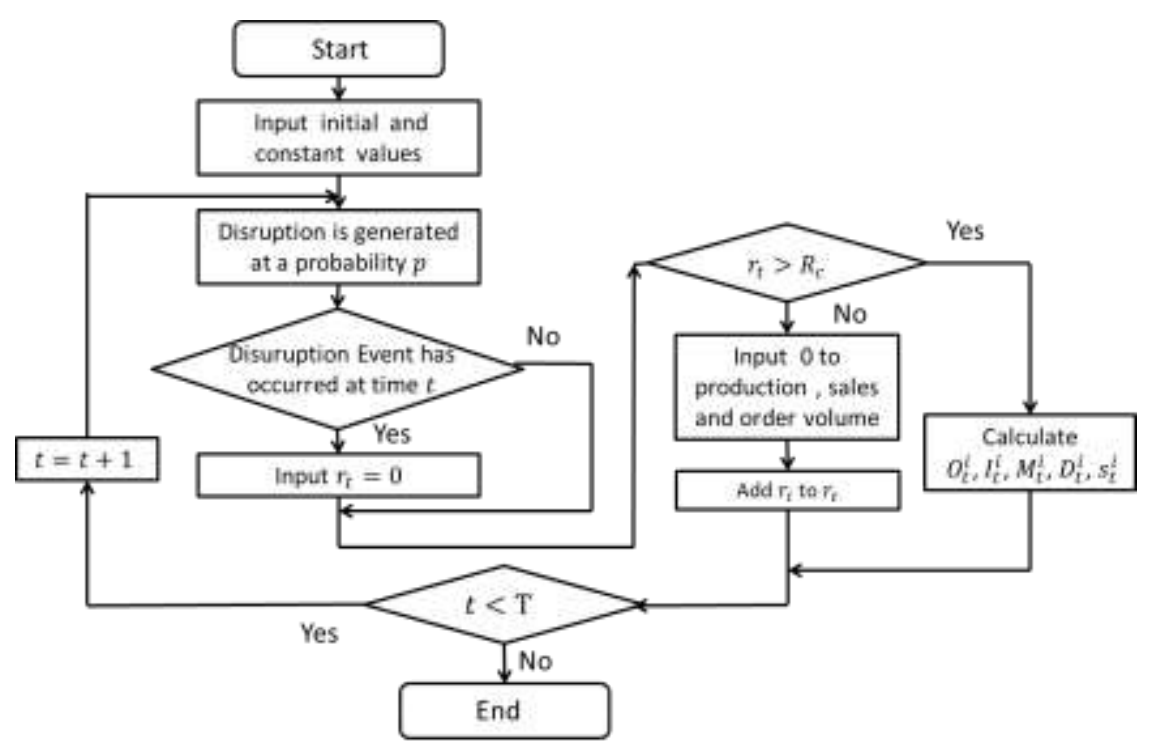

Fig. 5 Flowchart for tier 3 


\section{Simulation Results}

When the disruption time is calculated by numerical analysis, we set the parameters as follows: $T=15, D=100, R_{c}=10$, and $r_{i}=1$. Here, the disruption event occurred at time 2 .

Figure 6 shows the disruption period of each tier and the total disruption period when the initial inventory volume changed.

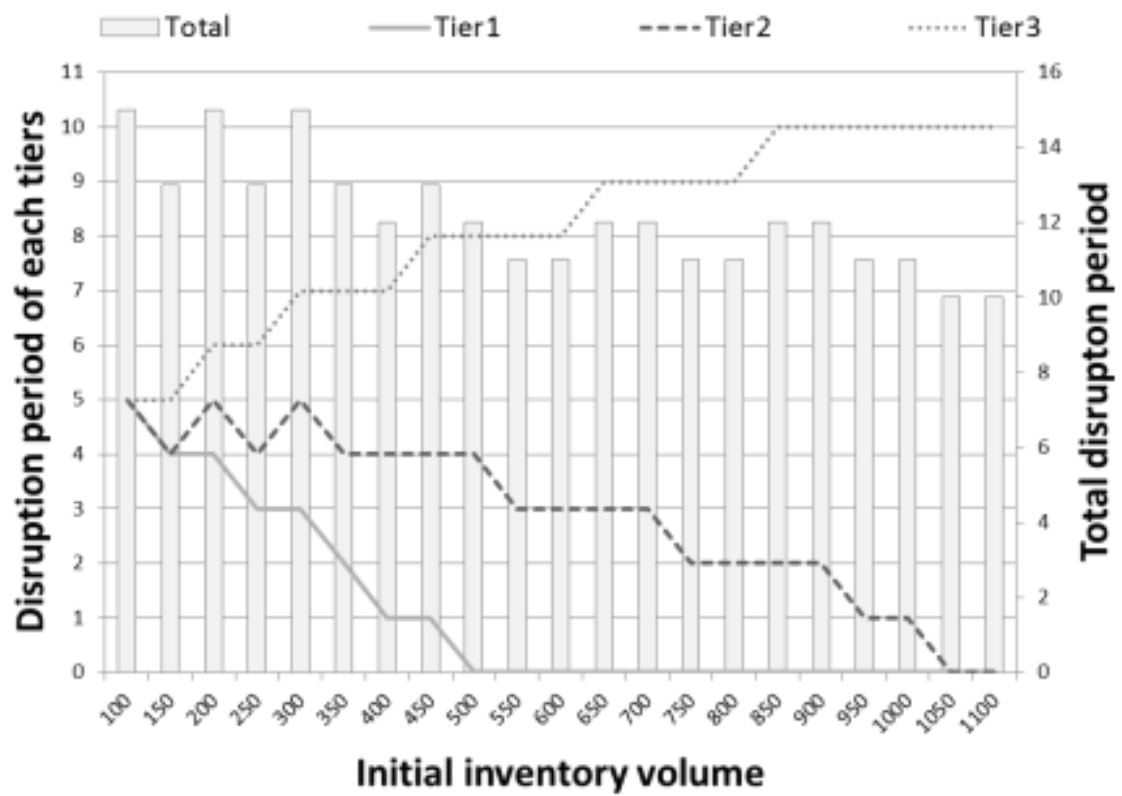

Fig. 6 Disruption period

The vertical axis is the stop period of each tier (left) and the total stop period (right). The horizontal axis is the initial inventory volume. In terms of mitigation, when the initial inventory volume increases, the total stop period and the stop period of each supplier tend to be reduced. However, in terms of responsiveness, we can see that the recovery time of tier 3 increases with increased initial inventory volume.

\section{Conclusion and Future Works}

We have designed an evaluation model for supply chains to clarify the conditions by which a buffer inventory can affect disruption while considering risk mitigation and responsiveness. Moreover, we have conducted a numerical experiment and calculated disruption times under arbitrary conditions. Consequently, we found that maintaining a buffer inventory can reduce disruption time. On the other hand, in terms 
of responsiveness, the time required for tier 3 to recover increases with increased initial inventory volume. In future, in addition to extending the supply chain model to be more realistic and applying the model to real problems, we plan to determine the optimal initial buffer inventory under arbitrary recovery constant from a ratio of sales price, manufacturing cost, and inventory cost. Thus, from a review of these parameters, it will become possible to consider how companies in different industries should maintain buffer inventories.

Acknowledgments This study was supported by the Ministry of Education, Culture, Sports, Science and Technology, Japan.

\section{References}

1. Kleindorfer, P. R., \& Saad, G. H.: Managing disruption risks in supply chains. Production and Operations Management, 14(1), 53-68 (2005)

2. Sheffi, Y.: The resilient enterprise: Overcoming vulnerability for competitive advantage. MIT Press (2005)

3. Knemeyer, A. M., Zinn, W., \& Eroglu, C. (2009). Proactive planning for catastrophic events in supply chains. Journal of Operations Management, 27(2), 141-153.

4. Tomlin, B.: On the value of mitigation and contingency strategies for managing supply chain disruption risks. Management Science, 52(5), 639-657 (2006)

5. Song, J., \& Zipkin, P. H.: Inventory control with information about supply conditions. Management Science, 42(10), 1409-1419 (1996)

6. Tainton, J., \& Nakano, M.: The behavioural effects of extreme events in global supply chains. Advances in production management systems. innovative and knowledge-based production management in a global-local world (pp. 62-70) Springer (2014)

7. Tomlin, B., \& Wang, Y.: On the value of mix flexibility and dual sourcing in unreliable newsvendor networks. Manufacturing \& Service Operations Management, 7(1), 37-57 (2005)

8. Dada, M., Petruzzi, N. C., \& Schwarz, L. B.: A newsvendor's procurement problem when suppliers are unreliable. Manufacturing \& Service Operations Management, 9(1), 9-32 (2007)

9. Tomlin, B.: Disruption - management strategies for short life - cycle products. Naval Research Logistics (NRL), 56(4), 318-347 (2009)

10. Krause, D. R., Handfield, R. B., \& Tyler, B. B.: The relationships between supplier development, commitment, social capital accumulation and performance improvement. Journal of Operations Management, 25(2), 528-545 (2007)

11. Krause, D. R.: Supplier development: Current practices and outcomes. International Journal of Purchasing and Materials Management, 33(1), 12-19 (1997)

12. Chopra, S., Reinhardt, G., \& Mohan, U.: The importance of decoupling recurrent and disruption risks in a supply chain. Naval Research Logistics (NRL), 54(5), 544-555 (2007) 